\title{
Handsearching the Journal of the Royal Army Medical Corps for Trials
}

\author{
Maj AMJ Croft \\ MA, MSc, MBBS, MIL, DMCC, MFPHM, RAMC \\ Consultant in Public Health Medicine
}

Headquarters Defence Secondary Care Agency, Ministry of Defence, St Giles' Court, London, WC2H 8LD

\author{
Lt Col DJ Vassallo \\ FRCS (Ed), RAMC \\ Consultant Surgeon
}

\author{
Mr M Rowe \\ BA (Hons) \\ Medical Librarian
}

Royal Hospital Haslar, Gosport, Hampshire, PO12 2AA.

SUMMARY: As part of the Cochrane Collaboration's international research endeavour, the authors carried out a handsearch of the RAMC Journal from 1948 to 1998, searching for randomised controlled trials (RCTs) and controlled clinical trials (CCTs). Ten trials were identified, of which 6 were RCTs and 4 were CCTs. The first trial was published in 1967. Four of the 10 identified trials were in the field of respiratory medicine, and 2 were in obstetrics and gynaecology. Of the 10 trials, only 3 had been found through a rigorous interrogation of Medline. The 7 newly identified trials were reported to the UK Cochrane Centre, and summary details of these trials were entered into Medline for use by clinicians and investigators in the future.

\section{Introduction}

The importance of trials

RCTs (Randomised controlled trials) are the most rigorous way of determining whether or not a causal relationship exists between a treatment and an outcome (1). Published reports of randomised clinical trials began to appear in the late $1940 \mathrm{~s}$, and it is generally accepted that the first ever report of an RCT was the October 1948 paper in the British Medical Journal comparing the effectiveness of streptomycin and bed rest versus bed rest alone in the treatment of pulmonary tuberculosis (2).

Random allocation of participants to an intervention or a control group is one of the key features of a true RCT. However in some trial settings the random allocation of participants may not be possible, or may not have been considered necessary by the investigators. Provided such a non-randomised trial has a control group which is broadly comparable to the intervention group, it will still yield evidence that is relatively bias-free, although not as strong as evidence from an RCT (3). These nonrandomised trials are known as CCTs.

There now exist large registers of health care trials, such as the Cochrane Collaboration's international register of controlled trials, which currently contains 158,000 trials (4). These registers are important for informing the decisions of clinicians, researchers and policy makers. Additionally, trial registers represent one source of primary studies for systematic reviews of RCTs, in which results from different trials are pooled through meta-analytic methods to arrive at the best estimate of treatment effect (5).

\section{The work of the Cochrane Collaboration}

Since its establishment in 1992, as part of the NHS Research and Development programme, one of the main achievements of the UK Cochrane Centre has been to add to the body of known clinical trials by laboriously seeking out published trials not indexed as such in any of the standard bibliographies or on-line databases (6). This deficiency may be because the study was incorrectly coded at time of indexing, or because the journal is a highly specialised one and hence not indexed at all. Alternatively, publication of the trial may have predated the institution of the main international databases: Medline, for example, was created in 1966 and routine indexing starts only in that year.

The work begun by the UK Cochrane Centre has since become a collaborative activity, co-ordinated by the Baltimore Cochrane Center in order to avoid duplication of effort. Under the direction of the Baltimore Center, affiliated individuals and groups throughout the world are now handsearching biomedical journals published from 1948 onwards, in order to locate and register reported but hitherto unidentified trials (7). The US National Library of Medicine, which owns Medline, has agreed to enlarge the database by creating electronic Medline records for all RCTs and CCTs identified through the Cochrane Collaboration, regardless of date or journal or language of publication.

This handsearch of the Journal of the Royal Army Medical Corps was undertaken as part of the Cochrane Collaboration's worldwide search for trials. For simplicity, the journal is referred to as the RAMC Journal throughout the remainder of this paper.

\section{Methods}

We began with a Medline search of the RAMC Journal, using a highly sensitive search strategy which has been developed by the Cochrane Collaboration (8). This search strategy consists of 26 successive queries based on Boolean logic and using the search terms "randomized controlled trial", "controlled clinical trial", "random allocation", "double-blind method", "singleblind method", "clinical trial" and "placebo".

The RAMC Journal first began to be indexed on Medline in 1990, and our initial electronic search yielded just four 'hits', all post-1990. One of these hits turned out not to be a trial at all, but to have been incorrectly coded as such.

We then searched by hand all back issues of the RAMC 
Journal from 1948 to the present day, carefully reading not only the text of all original papers, but the correspondence pages of the journal as well. We made photocopies of all the published RCTs and CCTs which we found. The work required close concentration and was mostly carried out in two-hour bursts over a period of about three months. We searched the most fruitful years (1967-77) twice, in order to ensure that we were not missing any trials.

In all, it took us 34 man-hours to complete a full handsearch of the RAMC Journal over the past 50 years.

\section{Results}

We identified a total of ten trials through handsearching, seven of which we had not found through our initial Medline search. Of these ten trials, six were RCTs (9-14) and four were CCTs (15-18). The first trial to appear in the RAMC Journal was published in 1967 (15). One of the recent RCTs had been reported as a letter to the editor (14) and did not show up on the initial Medline search. One older trial had also been published as a letter to the editor (17), but all the remainder appeared as full papers.

The methodological characteristics of the ten identified trials are summarised in Tables 1 and 2.

We forwarded hard copies of the seven 'new' trials to the UK Cochrane Centre in Oxford, and staff at the centre created electronic records for these trials, adding the records to the Cochrane Controlled Trials Register and at the same time passing them on to the Baltimore centre. In Baltimore the new RAMC Journal citations were submitted to the US National Library of Medicine, for coding in future releases of Medline as either RCT or CCT. All ten RAMC Journal trials are therefore now available to clinicians and investigators worldwide who have access to Medline.

\section{Discussion}

Limitations of Medline

This handsearch shows again the relatively poor sensitivity

and specificity of Medline as a means of identifying published trials. It also confirms the need to handsearch biomedical journals with the greatest of care, paying special attention to the Correspondence section of the journals being searched. These general issues have been discussed in detail elsewhere (6).

Of the ten controlled trials published in the RAMC Journal since 1948 and identified through this search, it is noteworthy that four are in the specialty of respiratory medicine. This reflects the long-established tradition of clinical excellence in chest medicine which RAMC physicians have maintained over the years.

\section{Need for more military trials}

We were surprised to find no published trials at all in the RAMC Journal in the fields of military surgery or military psychiatry, since these are generally regarded as "core" military specialties. The structured training programmes introduced as part of the Calman reforms recommend that Specialist Registrars should be involved in appropriate, high-quality research (19). All military clinicians have access to a disciplined, homogeneous study population of young adults, usually with well-defined pathology. Clinical directors in military hospitals should therefore encourage their Specialist Registrars to undertake controlled clinical trials in areas of specific military interest, in preference to less demanding (but ultimately less valuable) research options, such as uncontrolled cohort studies or questionnaire-based surveys.

The success of a clinical trial will depend on meticulous planning, and on the adoption of a truly random method of allocating participants to either the intervention or the control arms of the study (1). Such a method might comprise a system of central randomisation (in the case of a surgical intervention), or the use of serially-numbered, opaque, sealed envelopes (for a pharmaceutical trial). Only two of the ten trials published in the RAMC Journal included a specific mention in their Methods section of an adequate system for concealing allocation $(11,13)$.

Table 1

Randomised controlled trials published in the RAMC Journal 1948-98

\begin{tabular}{|lcccc|}
\hline Trial identifier & Design & Participant type & Participant numbers & Clinical specialty \\
\hline Duncan 1974 & Parallel group & Postpartum females & 80 & Obstetrics \& gynaecology \\
\hline George \& Menzies 1975 & Parallel group & Anxious adult patients & 53 & Primary care \\
\hline Sinclair \& Winfield 1990 & Cross-over & Young adult asthmatics & 20 & Respiratory medicine \\
\hline Bricknell 1991 & Parallel group & Parachuting soldiers & $4 *$ & Occupational medicine \\
\hline Lyall 1991 & Cross-over & Consecutive dental patients & 148 & Oral/Maxillofacial surgery \\
\hline McCullough 1992 & Parallel group & Postnatal females & 70 & Obstetrics \& gynaecology \\
\hline
\end{tabular}

Table 2

Controlled clinical trials published in the RAMC Journal 1948-98

\begin{tabular}{|c|c|c|c|c|}
\hline Trial identifier & Design & Participant type & Participant numbers & Clinical Specialty \\
\hline Power 1967 & Parallel group & Schoolchildren & 263 & Respiratory medicine \\
\hline Eade \& Mackay-Dick 1968 & Parallel group & Gurkha soldiers & 147 & Respiratory medicine \\
\hline Power 1969 & Parallel group & Schoolchildren & 103 & Resipiratory medicine \\
\hline Miles 1977 & Parallel group & Confirmed shigellosis cases & 61 & Gastroenterology \\
\hline
\end{tabular}


Journal from 1948 to the present day, carefully reading not only the text of all original papers, but the correspondence pages of the journal as well. We made photocopies of all the published RCTs and CCTs which we found. The work required close concentration and was mostly carried out in two-hour bursts over a period of about three months. We searched the most fruitful years (1967-77) twice, in order to ensure that we were not missing any trials.

In all, it took us 34 man-hours to complete a full handsearch of the RAMC Journal over the past 50 years.

\section{Results}

We identified a total of ten trials through handsearching, seven of which we had not found through our initial Medline search. Of these ten trials, six were RCTs (9-14) and four were CCTs (15-18). The first trial to appear in the RAMC Journal was published in 1967 (15). One of the recent RCTs had been reported as a letter to the editor (14) and did not show up on the initial Medline search. One older trial had also been published as a letter to the editor (17), but all the remainder appeared as full papers.

The methodological characteristics of the ten identified trials are summarised in Tables 1 and 2.

We forwarded hard copies of the seven 'new' trials to the UK Cochrane Centre in Oxford, and staff at the centre created electronic records for these trials, adding the records to the Cochrane Controlled Trials Register and at the same time passing them on to the Baltimore centre. In Baltimore the new RAMC Journal citations were submitted to the US National Library of Medicine, for coding in future releases of Medline as either RCT or CCT. All ten RAMC Journal trials are therefore now available to clinicians and investigators worldwide who have access to Medline.

\section{Discussion}

Limitations of Medline

This handsearch shows again the relatively poor sensitivity

and specificity of Medline as a means of identifying published trials. It also confirms the need to handsearch biomedical journals with the greatest of care, paying special attention to the Correspondence section of the journals being searched. These general issues have been discussed in detail elsewhere (6).

Of the ten controlled trials published in the RAMC Journal since 1948 and identified through this search, it is noteworthy that four are in the specialty of respiratory medicine. This reflects the long-established tradition of clinical excellence in chest medicine which RAMC physicians have maintained over the years.

\section{Need for more military trials}

We were surprised to find no published trials at all in the RAMC Journal in the fields of military surgery or military psychiatry, since these are generally regarded as "core" military specialties. The structured training programmes introduced as part of the Calman reforms recommend that Specialist Registrars should be involved in appropriate, high-quality research (19). All military clinicians have access to a disciplined, homogeneous study population of young adults, usually with well-defined pathology. Clinical directors in military hospitals should therefore encourage their Specialist Registrars to undertake controlled clinical trials in areas of specific military interest, in preference to less demanding (but ultimately less valuable) research options, such as uncontrolled cohort studies or questionnaire-based surveys.

The success of a clinical trial will depend on meticulous planning, and on the adoption of a truly random method of allocating participants to either the intervention or the control arms of the study (1). Such a method might comprise a system of central randomisation (in the case of a surgical intervention), or the use of serially-numbered, opaque, sealed envelopes (for a pharmaceutical trial). Only two of the ten trials published in the RAMC Journal included a specific mention in their Methods section of an adequate system for concealing allocation $(11,13)$.

Table 1

Randomised controlled trials published in the RAMC Journal 1948-98

\begin{tabular}{|lcccc|}
\hline Trial identifier & Design & Participant type & Participant numbers & Clinical specialty \\
\hline Duncan 1974 & Parallel group & Postpartum females & 80 & Obstetrics \& gynaecology \\
\hline George \& Menzies 1975 & Parallel group & Anxious adult patients & 53 & Primary care \\
\hline Sinclair \& Winfield 1990 & Cross-over & Young adult asthmatics & 20 & Respiratory medicine \\
\hline Bricknell 1991 & Parallel group & Parachuting soldiers & $4 *$ & Occupational medicine \\
\hline Lyall 1991 & Cross-over & Consecutive dental patients & 148 & Oral/Maxillofacial surgery \\
\hline McCullough 1992 & Parallel group & Postnatal females & 70 & Obstetrics \& gynaecology \\
\hline
\end{tabular}

Table 2

Controlled clinical trials published in the RAMC Journal 1948-98

\begin{tabular}{|c|c|c|c|c|}
\hline Trial identifier & Design & Participant type & Participant numbers & Clinical Specialty \\
\hline Power 1967 & Parallel group & Schoolchildren & 263 & Respiratory medicine \\
\hline Eade \& Mackay-Dick 1968 & Parallel group & Gurkha soldiers & 147 & Respiratory medicine \\
\hline Power 1969 & Parallel group & Schoolchildren & 103 & Resipiratory medicine \\
\hline Miles 1977 & Parallel group & Confirmed shigellosis cases & 61 & Gastroenterology \\
\hline
\end{tabular}


In carrying out military trials it is tempting to use a military sub-grouping (for example, a platoon or company) as the functional unit of allocation. This is administratively very much easier than randomising by individual trial participants, and was the allocation technique used in one of the trials we identified (12). However this practice weakens the statistical power of a study and can introduce bias, and should be avoided (20).

In reporting a trial there is now an obligation on all triallists to set out their findings in a standardised format, so as to facilitate external critical appraisal of their conclusions, and also to make the trial results as accessible as possible to future researchers $(21,22)$. It is generally recommended also that a published trial should be given an "indicative" title: that is, the title should include the words "randomised controlled trial" or "controlled clinical trial". This has now become standard practice in the mainstream biomedical journals.

\section{An international database of military trials}

It is gratifying to find that research of high scientific quality has been, and continues to be published in the RAMC Journal. Many RAMC medical officers of course have carried out clinical trials alone or in collaboration with other investigators, and have reported their trials in some forum other than the RAMC Journal. An international database of all military medical trials is currently being established in the Medical Library at the Royal Hospital Haslar. This database will be wholly electronic, and by the end of 1998 it will be posted on the hospital's web site.

As part of the continuing research effort of the Cochrane Collaboration, we are currently handsearching a number of other military medical journals besides the RAMC Journal. We will be reporting the results of these further searches in the near future.

\section{Acknowledgements}

We undertook this work as a contribution towards the Centenary Year of the Royal Army Medical Corps. We thank Steve McDonald of the UK Cochrane Centre and Anita MillerHart of the Baltimore Cochrane Center for their helpful advice, and Roger Brand for administrative support.

\section{REFERENCES}

1. SibBald S, Roland M. Why are randomised controlled trials important? BMJ 1998; 316: 201.

2. Streptomycin in Tuberculosis Trials Committee, Medical Research Council. Streptomycin treatment of pulmonary tuberculosis: a Medical Research Council investigation. BMJ 1948; ii: 769-782.

3. Guyatt GH, Sackett DL, Sinclair JC, Hayward R, CoOK DJ, COOK RJ. User's guide to the medical literature. IX. A method for grading health care recommendations. JAMA 1995; 274: 1800-1804.

4. The Cochrane Library [database on disk and CD-ROM]. Oxford: Update Software, April 1998. Updated quarterly.

5. Davey Smith G, EgGer M. Meta-analysis. Unresolved issues and future developments. Lancet 1998; 316: 221225.

6. Chalmers I, Dickersin K, Chalmers TC. Getting to grips with Archie Cochrane's agenda. BMJ 1992; 305: 786-788.

7. DiCKERSIN K, SCHERER R, LEFEBVRE C. Identifying relevant studies for systematic reviews. BMJ 1994; 309: 1286-1291.

8. Cochrane Collaboration Handbook. Oxford: Cochrane Collaboration, 1998. Updated annually.

9. DUNCAN RW. Inhibition of lactation in a military hospital maternity unit. J R Army Med Corps 1974; 120: 99-101.

10. GEORGE RD, MENZIES RC. A comparison of amitriptyline with chlordiazepoxide in anxiety. $J R$ Army Med Corps 1975; 121: 193-196.

11. SinClaiR DG, WINFIELD CR, Attenuation of exercise induced asthma by nedocromil sodium and sodium cromoglycate. J R Army Med Corps 1990; 136: 105-106.

12. BRICKNELL MCM. Sleep manipulation prior to airborne exercises. J R Army Med Corps 1991; 137: 22-26.

13. LYALL JB. Third molar surgery: the effect of primary closure wound dressing and metronidazole on postoperative recovery. J R Army Med Corps 1991; 137: 100-103.

14. McCullough AM. Salt baths. J R Army Med Corps 1992; 138: 101.

15. POWER JGP. Intradermal BCG vaccination by dermo-jet. J R Army Med Corps 1967; 113: 197-201.

16. EADE AWT, MACKAY-DiCK J. Comparison of a daily and alternate-day dual drug regime of chemotherapy in the treatment of pulmonary tuberculosis. J R Army Med Corps 1968; 114: 73-78.

17. POWER JGP. Intradermal BCG vaccination by dermo-jet. $J R$ Army Med Corps 1969; 115: 98-99.

18. Miles RN. Bacillary dysentery in Cyprus. J R Army Med Corps 1977; 123: 42-44.

19. Department of Health. Hospital doctors: training for the future. Report of the Working Group on Specialist Medical Training (the Calman Report). Heywood: Health Publications Unit, 1993.

20. LILIENFELD DE, STOLLEY PD. Foundations of epidemiology. 3rd ed. Oxford: OUP, 1994.

21. ScHulz KF. Randomised trials, human nature, and reporting guidelines. Lancet 1996; 348: 596-598.

22. Begg C, Cho M, Eastwood S, Horton R, Moher D, Olkin I, et al. Improving the quality of reporting of randomized controlled trials: the Consort statement. JAMA 1996; 276: 637-639. 